\title{
Hypersensivity reactions to steroids: Review
}

\author{
Collado Chagoya Rodrigo*, Cruz Pantoja Ruben Alejandro, Hernández Romero Javier, León Oviedo Cristobal, Campos Gutiérrez Rosa \\ Isela, Velasco Medina Andrea and Velázquez Sámano Guillermo
}

Department of Clinical Immunology and Allergy, Hospital General De México. (Dr Eduardo Liceaga), Mexico

\section{History}

The history of corticosteroids begins in the year of 1855 when Thomas Addison describes a "state of generalized languor, failure in the function of the heart, irritability in the stomach and changes of coloration in the skin", initially called melanodermia and later called Addison's disease, characterized by the lack of a substance produced in the adrenal glands [1].

Later in 1929 Thomas Hench discovered the presence of a substance that in pregnant women caused remission of the symptoms of Rheumatoid Arthritis by calling it substance X, acquiring until the 1930s the name of cortisone, given by Calvin Kendall because that substance came from the adrenal cortex, receiving both in 1950 (Hench and Kendall) the Nobel Prize in Medicine for his findings in cortisone $[2,3]$.

\section{Chemical structure}

In humans, all steroid hormones are derived from cholesterol. Cholesterol is in turn synthesized de novo from acetate ( 90\%) or obtained from the diet $(\sim 10 \%)$. The production of the steroids involves a number of precise modifications to the cholesterol structure, including attack at the $11,16,17,18,19,20$, and 21 positions, conversion of the 3-hydroxyl to a ketone, and isomerization of the 5-6 double bond to the $4-5$ position. The basic structure of most steroid hormones has three rings of six carbon atoms and one ring of five, the cyclopentanoperhydrophenanthrene nucleus. There is a chemical nomenclature for each steroid that uniquely denotes the structure for that compound. This nomenclature is based on describing the modifications to one of four possible backbones [4,5] (Figure 1).

The differences between cholestane (which has 27 carbons), pregnane (which has 21 carbons), and androstane (which has 19 carbons) are limited to the length of the side-chain at the $17 \beta$ position. Estrane differs from androstane in that it lacks the 19-methyl group $[4,5]$.

In human endocrine physiology, there are three major classes of steroid hormones: glucocorticoids (GCs:Affect energy metabolism), mineralocorticoids (MCs: electrolyte.regulating activity), and the sex steroids (affect sexual development and reproductive functioning) [4,5] (Figure 2).

\section{Mechanisms of action}

GCs are the most potent and effective drugs in the prevention and suppression of inflammation caused by mechanical, chemical, infectious and immunological stimuli. The mechanisms of action of steroids can be divided into mechanisms of genomic action and mechanisms of non-genomic action.

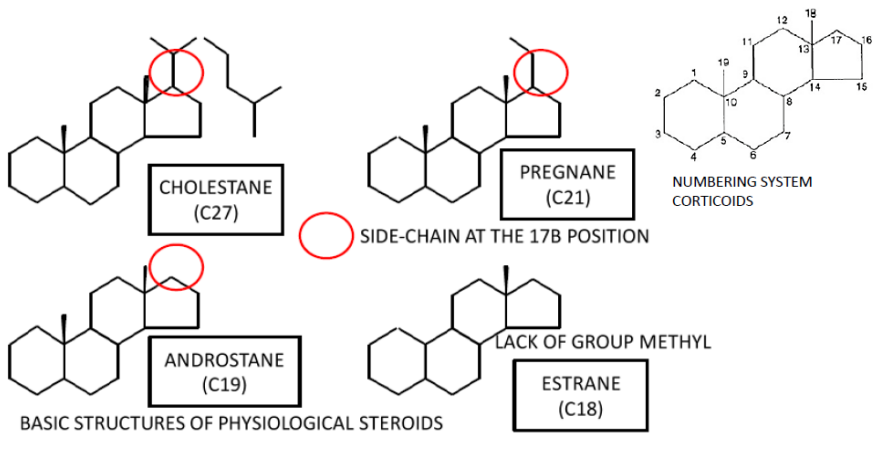

Figure 1. Basic structures of physiological steroids

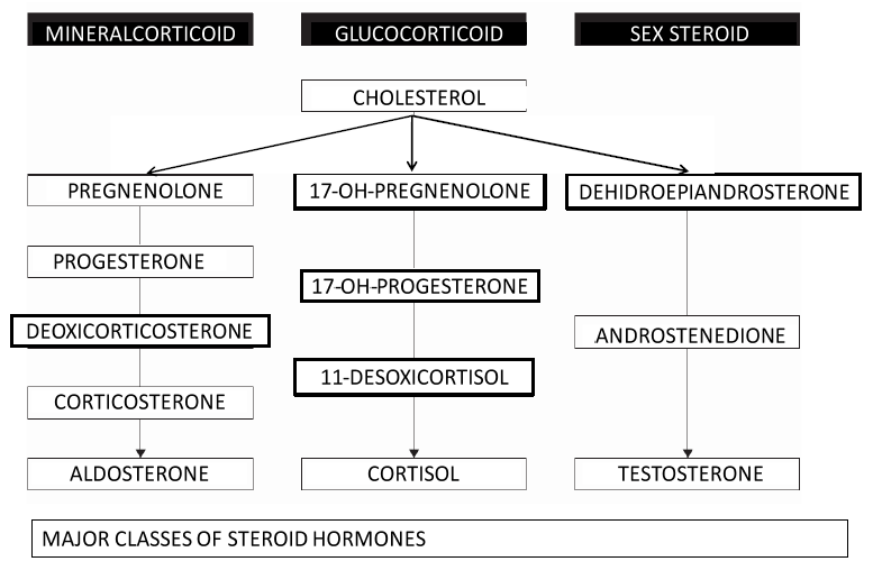

Figure 2. Major classes of steroid hormones

Genomic steroid action consists of direct regulation of gene transcription by ligand-receptor interaction or indirect modulation of coactivators. Biochemical effects (including side effects) of steroids may be categorized according to the various receptor types, i.e., androgen (hAR), estrogen, glucocorticoid (hGR), progesterone (hPR) and mineralcorticoid receptors $[6,7]$.

These receptors act as transcription factors to regulate gene expression by recognizing palindromic hormone response elements

*Correspondence to: Rodrigo Collado Chagoya, MD, Hospital General Mexico, Inmunologia Clinica Alergia, Medicina Interna, Calle Balmis Sn, Doctores Ciudad De Mexico, Mexico, E-mail: rodnova87@hotmail.com

Key words: corticosteroids, hypersensivity reactions, steroids, cholesterol

Received: May 29, 2018; Accepted: June 06, 2018; Published: June 12, 2018 
(HRE) at the DNA after homo- or heterodimerization of the ligandreceptor complex. The activated receptor interacts with DNA and with other nuclear proteins, resulting in a change in the rate of mRNA transcription. The genomic effects of steroids in general are slow, with persistence of effect for hours / months.

Non-genomic mechanisms are those that do not involve GR: They would occur at high concentrations of GC and would be the consequence of physicochemical interactions with the membrane cellular plasma and mitochondrial membrane. Normally the nongenomic effects are of rapid appearance and of short duration.

One example of a nongenomic effect is the Acute behavioral changes induced by corticosteroids through a glycoprotein acid cytosolic receptor (protein G) that would modulate the speed of neuronal discharge or modify the reuptake extraneuronal neurotransmitter (transporter of cations).

The main anti-inflammatory effect of GCs is based on the inhibition of the genetic transcription of numerous genes that encode proinflammatory proteins, which include numerous cytokines -interleukins (IL). 1, 2, 3, 4, 5, 6, 11 and 13, the tumor necrosis factor alpha, the granulocyte and macrophage colony stimulating factor (GM-CSF) -, chemokines (IL-8, RANTES, monocyte chemotactic proteins 1, 2, 3 and 4, eotaxin), adhesion molecules (intracellular adhesion molecule 1, vascular cell adhesion molecule 1, E-selectin) and regulatory enzymes for the synthesis of mediators (inducible nitric oxide synthetase, cyclooxygenase 2, phospholipase A2.) This antiinflammatory effect is also through the synthesis of anti-inflammatory proteins, such as lipocortin 1, SLPI (serum leukoprotease inhibitor), IL10 or the antagonist of IL-1 receptors [6,7].

Other physiological effects in the use of glucocorticoids are the increase in blood glucose through the stimulation of liver gluconeogenesis, also Glucocorticoids enhances oxidation of fatty acids in cells and decrease the protein synthesis causing the decline of protein stores essential in all body cells clinically translated into growth slowing, skin atrophy, increased capillary fragility, bruisingvand striae, inhibits osteoblastic function (osteopenia), increase blood pressure by a variety of mechanisms involving actions on the kidney and vasculature like reducing nitric oxide-mediated endothelial dilatation, raise intraocular pressure through an increase in aqueous humor production, suppress thyroid axis through a direct action on thyroid stimulating hormone secretion (TSH), decrease calciumabsorption from the gut and increase urinary calcium excretion, increase Renal excretion of urate, induce specific kinases for synthesis of phospholipids in the pregnant lung (surfactant) or induce the synthesis of b2 adrenoceptors in bronchial smooth muscle (bronchodilation) [6,7].

\section{Pharmacodinamy and pharmacokinetics}

Systemically used GC are classified as short acting (S:6-12 hours), intermediate acting (I: 12-36 hours) and long acting (L: 36-73 hours) based on their duration of ACTH suppression and by their relative GC versus MC potency, these relative potencies of CS differ due to their affinity for the receptor $[8,9]$ (Table 1 ).

Glucocorticoids are active by any route of administration. Times at maximum concentration $\mathrm{c}(\mathrm{tmax})$ orally are reached around $90 \mathrm{~min}$. In IM or IV route, the soluble esters (phosphate) are hydrolyze rapidly by tissue esterases or plasma levels, releasing the steroid with a $t^{1 / 2}$ of $10 \mathrm{~min}$; by IM route the $t_{\text {max }}$ is obtained between 15 and $30 \mathrm{~min}$. Most glucocorticoids (except for hydrocortisone) bind albumin to a greater degree and while they keep their water-soluble ester they are free. Their apparent volumes of distribution (Vd) oscillate between 0.5 and $21 / \mathrm{kg}$. Glucocorticoids are eliminated by metabolism hepatic, so the fraction of excretion urinary active drug is less than $20 \%$. All metabolites resulting are conjugated with glucuronic acid or with sulfate and are eliminated by renal or biliary $[8,9]$.

\section{Hypersensivity reactions}

Broadly, hypersensitivity reactions to steroids are divided into two categories: immediate reactions (Urticaria, Anaphylaxis, bronchospasm, etc..) typically occurring within $1 \mathrm{~h}$ of drug administration, and delayed reactions (Contact Dermatitis, etc..), which occur more than an hour after drug administration. Of the types of Hypersensitivity Reactions to Steroids, Delayed Hypersensitivity Reactions (type IV) are much more frequent with an estimated incidence of Contact dermatitis to corticosteroids of $0.5-5 \%$. These delayed hypersensitivity reactions occur more readily following topical exposure to corticosteroids than via other routes of administration [10-12]. In order of presentation, hypersensitivity reactions are more frequent to topical administration followed by intravenous administration and, to a lesser extent, inhaled and nasal administration [13].

While the presentation of immediate hypersensivity reactions has a lower prevalence calculated of $0.1-0.5 \%$, being the risk factors more

Table 1. Pharmacokinetic characteristics of glucocorticoids

\begin{tabular}{|c|c|c|c|c|c|c|c|c|c|c|}
\hline DRUG & $\begin{array}{c}\text { Oral A.B. } \\
\text { (\%) }\end{array}$ & Cmax & $\operatorname{Tmax}(h)$ & Vd (l/kg) & $t^{1} / 2:$ (h) & $\begin{array}{c}\text { Protein Union } \\
(\%)\end{array}$ & $\begin{array}{c}\text { Urinary } \\
\text { Excretion (\%) }\end{array}$ & Duration & \multicolumn{2}{|c|}{$\begin{array}{l}\text { Potency } \\
\text { GC/MC }\end{array}$} \\
\hline Betametasone & 90 & $80-115$ & $1.5-2$ & 1.2 & 6 & 64 & 5 & $\mathrm{~L}$ & 35 & 0 \\
\hline Dexametasone & 86 & $100-170$ & 2 & 2 & $3-5$ & $66-70$ & $30-40$ & $\mathrm{~L}$ & 30 & 0 \\
\hline Deflazacort & $>80$ & 132 & 2 & 1.5 & 2 & 40 & 18 & I & 2.8 & 0 \\
\hline Hidrocortisone & $26-96$ & 300 & 1 & 0.5 & $1-2$ & 90 & 1 & $\mathrm{~S}$ & 1 & 1 \\
\hline Prednisone & 80 & 200 & 2.5 & 0.9 & 3.5 & 95 & 15 & I & 4 & 0.8 \\
\hline Prednisolone & 82 & 460 & 1.5 & 0.6 & 3 & 90 & 15 & I & 4 & 0.8 \\
\hline Metilprednisolone & $80-89$ & 300 & $1-2$ & 1.5 & $2-3$ & 77 & 1 & I & 5 & 0.5 \\
\hline Triamcinolone & 23 & $10-20$ & $1-2$ & 1.5 & 3.5 & $<50$ & 15 & I & 5 & 0 \\
\hline Fludrocortisone & 97 & $80-125$ & 1.5 & 1 & 3.5 & 75 & 80 & I & 10 & 125 \\
\hline Parametasone & 100 & $30-90$ & 1.5 & 1 & 4 & 70 & 80 & I & 10 & 0 \\
\hline Beclometasone (I) & 20 & & & 4.3 & $0.5-2$ & 87 & & & 0.6 & 0 \\
\hline Budesonide (I) & 11 & & & 3 & $15-2$ & 88 & & & 1 & 0 \\
\hline Fluticasone (I) & $<1$ & & & 3.7 & $3-7$ & 90 & & & 1 & 0 \\
\hline Mometasone (I) & $<1$ & & & 2.5 & 4.5 & 99 & & & 0.8 & 0 \\
\hline
\end{tabular}

A..B. Absolute Bioavailability, Cmax; Maximum serum concentration, tmax: Time during Cmax is reached. ; $\mathrm{t}^{1} \mathrm{2}:$ :Elimination half-life, vd: apparent volume of distribution, S:Short (6-12 hrs), I: Intermediate (12-36 hrs), L:Large (36-72hrs). (I): Inhalated 
commonly associated the chronic use of steroids, high doses of steroids, hypersensitivity to NSAIDS and the most associated steroids are the hydrocortisone, prednisone and methylprednisolone [10-12].

\section{Pathogenesis}

Bundgaard has proposed a possible mechanism of allergy for nonmediated IgE Reactions, which is at least partly due to a steroid-glyoxal, a degradation product of cortisol and hydrocortisone, with an aldehyde group in the $\mathrm{C} 21$ position easily forms Schiff bases with reactive carbonyl groups of lysine or arginine, in this way being responsible for irreversible bonding to the guanidinic groups of arginine, thus forming a stable hapten for the presentation of the steroid carbon rings to the body immune system $[14,15]$.

Glyoxal or Ethanedial is a 2-carbon aldehyde with carbonyl groups on both carbons whose molecular formula is $\mathrm{C}_{2} \mathrm{H}_{2} \mathrm{O}_{2}$ or OHCCHO through the controlled oxidation of ethanol with nitric acid, is the simplest of the dialdehydes (two aldehyde groups) and can function like a hapten to drive a hypersensivity reaction, and this haptenized steroid, specially its rings estrcture can cause an immunological reaction in future re- exposures. [14,15] (Figure 3).

IgE Reactions may be induced by salts, such as succinate or rarely by certain diluents such as carboxymethylcellulose or metabisulfite. Succinate as an ingredient is more likely to have an allergic reaction compared to others such as sodium phosphate, because the succinate esters have greater solubility in water and high affinity for different serum proteins, which can lead to an IgE-mediated reaction and gives it an immunogenic role. Due to the structural similarity of the succinate (and to a lesser extent acetate) radicals to the steroid-glyoxal it is possible that these succinate radicals are able to mimic the ability of the steroid glyoxal to bind the arginine guanidine groups in the albumin of human serum in a more efficient way than acetate radicals. [14,15].

In the case of topic reactions, the most common antigen is cortisol which has low molecular weight and high lipofilicity, both charateristics for an ideal allergen, but at other times the reaction may be due to other constituents of the creams, such as neomycin or cetylesteryl alcohol $[16,17]$.

The most common hypersensvity reactions to steroids are nonmediated IgE reactions being mediated by direct activation of components of innate immune system (Mast cells, basophils, and the complement Cascade) $[16,17]$.

\section{Cross-reactivity}

Along with the allergic reactions observed in specific steroids, it was evident that some patients reported positive results to patch tests for corticosteroids with which they had not previously been exposed. This indicated the existence of cross-reactivity among other corticosteroids

In 1989 Coopman, et al. [18,19] classified these drugs into four groups based on the results of the corticosteroid patch tests and their chemical structure and subsequently validated by Lepoittevin, et al. validated these classifications in 1995 by computational conformational analysis and Goossens, et al. In 2000 based on skin patch test results obtained from a large cohort of corticosteroid allergic patients [20].

The groups of cross-reacting molecules are classified into: Group A (hydrocortisone type: no substitution on the D ring except a short chain ester on C2 or a thioester on C21); Group B (triamcinolone acetonide type: Acetonides. C16, C17-cis-ketal or -diol structure), Group C (betamethasone type: Methylation on C16) and D (hydrocortisone- 17-butyrate type). Subsequently group D was subdivided into two groups (D1 and D2) depending on the presence or absence of a C16 methyl substitution and/or halogenation at C9 of ring $\mathrm{B}$. There is a high cross-reactivity between corticosteroids in each group, as well as between group D2 and groups A and B. Hydrocortisone-17-butyrate from group D2 in the skin is enzymatically converted to hydrocortisone of group A. In the same way other corticosteroids may generate cross-reactivity with group A, for example the methyl-prednisolone aceonate of group D2 becomes subsequent to several enzymatic steps in methylprednisolone (group A) and the prednicarbate of group D2 becomes prednisolone (also of group A) And corticosteroids from the group D1 shows a minimal low cross-reactivity with the other groups [19,20] (Table 2).

\section{Diagnosis}

As in any Adverse Drug Reaction (ADR) the diagnosis is primarily clinical, demonstrating a temporal-causal relationship between the clinical reaction and the steroid, however to is of primary importance to differentiate between $\operatorname{IgE}$ mediated and non $\operatorname{IgE}$ mediated hypersensivity Reaction. Currently there are several diagnostic studies that can suppot the diagnosis of Steroid Allergy but unfortunately there are no standardized tests to confirm steroid allergies [21,22] (Figure 4).

In the case of an Immediate IgE Hypersensivity Reaction, test in vitro with ImmunoCAP is only available for Dexamethasone and the sensitivity and specificity is unknown, skin testing can provide sufficient information for a diagnosis of corticosteroid-associated immediate hypersensitivity with a higher sensitivity and negative predictive value than in vitro test (Figure 4).

In the case of Immediate non IgE Hypersensivity Reaction, the only available in vitro test is the Basophil Activation Test, while the Skin testing are not validated and lack specificity and sensitivity, so in cases of diagnostic suspicion the gold standard will be the Challenge Provocation Testing [21,22].

In the case of Delayed Hypersensivity Reactions, the diagnosis can be supported with positive patch test or test of cellular immunity such

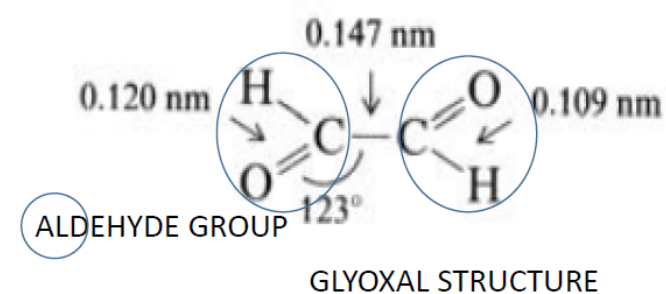

Figure 3. Glyoxal structure
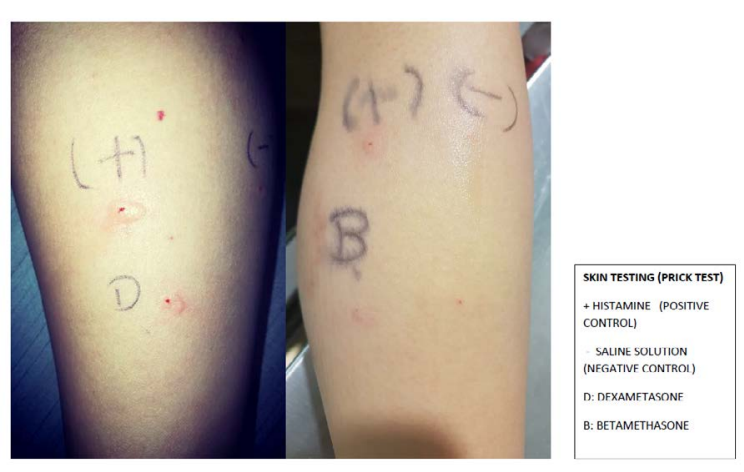

Figure 4. Delayed Hypersensivity Reactions 
Table 2. Groups of cross-reacting molecules classification

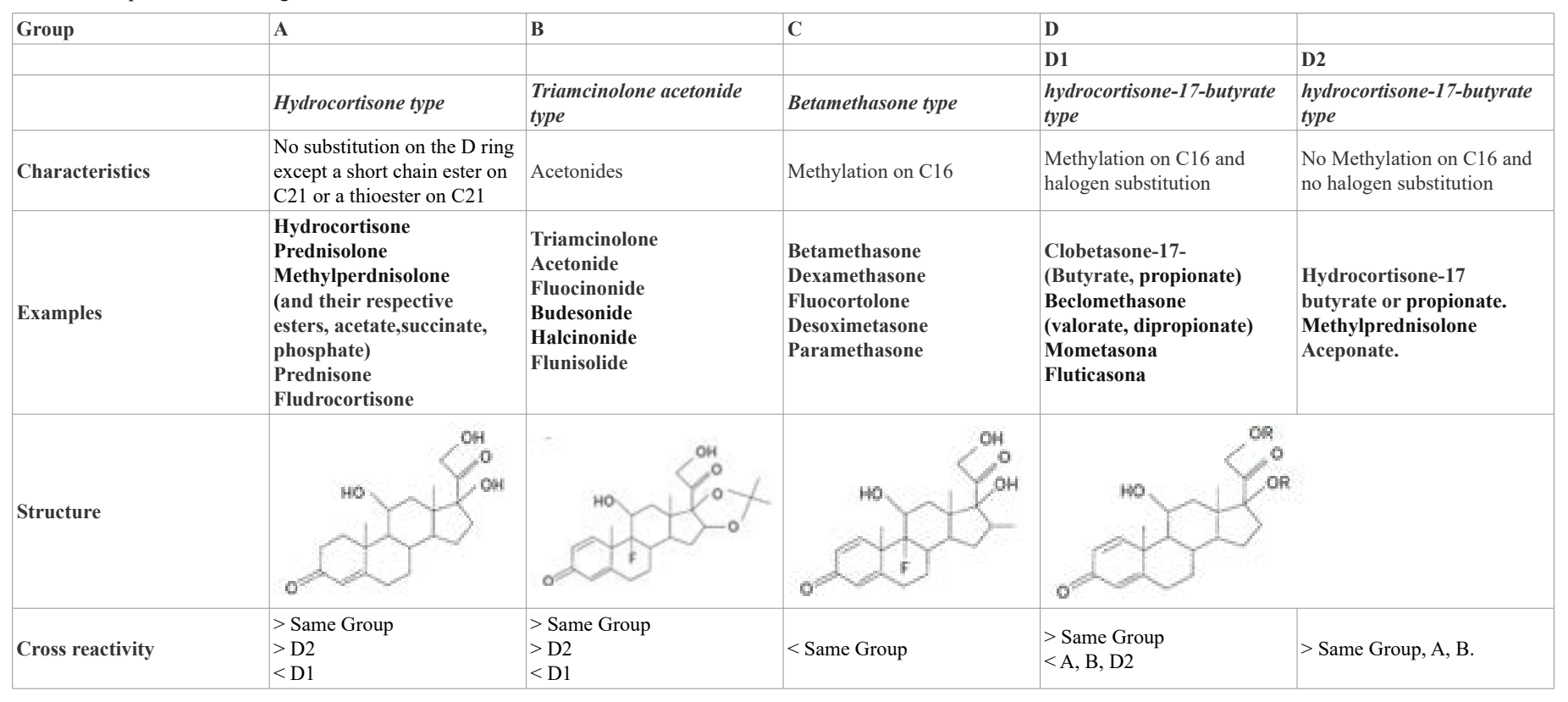

as Lymphocyte Transformation Test (LTT) and in the same way of non IgE Reactions, in cases of diagnostic suspicion the gold standard will be the Challenge Provocation Testing.

Steroids allergy is not typically drug-specific and co-sensitizations or cross-reactivity between members of the same family are common. Therefore, it is recommended to study steroids by group of families based on Coopman (or ABCD) classification system, when a true hypersensivity reaction is presented in order to offer a therapeutic alternative $[21,22]$.

\section{Treatment}

The main treatment consists of avoiding re-exposure to the causative drug and offering an alternative treatment by administering a steroid from a different structural group, considering group $\mathrm{C}$ of Coopman System Classification are the steroids with less allergenicity such as betamethasone and dexamethasone or a new order steroid like deflazacort, and only in case of no alternative of treatment to assess desensitization (currently cases of successful desensitization to dexamethasone, hydrocortisone, prednisone and methylprednisolone) $[23,24]$.

\section{References}

1. Lovas K, Husebye E (2004) Addison's disease. The Lancet 365: 2058-2061.

2. Ingle DJ (1974) Edward C Kendall. Biogr Mem Natl Acad Sci 47: 249-290.

3. Kirwan JR, Bálint G, Szebenyi B (1999) Anniversary: 50 years of glucocorticoid treatment in rheumatoid arthritis. Rheumatology (Oxford) 38: 100-102. [Crossref]

4. Payne AH, Hales DB (2004) Overview of steroidogenic enzymes in the pathway from cholesterol to active steroid hormones. Endocr Rev 25: 947-970. [Crossref]

5. Aron DC, Findling JW, Tyrrell JB (2011) Glucocorticoids \& adrenal androgens. In: Gardner DG, Shoback D, eds. Greenspan's basic \& clinical endocrinology, 9th ed. New York: Lange, McGraw Hill, 346-395.

6. Adcock IM, Ito K (2000) Molecular mechanisms of corticosteroid actions. Monaldi Arch Chest Dis 55: 256-266. [Crossref]

7. Barnes PJ (2006) Corticosteroid effects on cell signalling. Eur Respir J 27: 413-416. [Crossref]
8. Scheuer E, Warshaw E (2003) Allergy to corticosteroids: update and review of epidemiology, clinical characteristics, and structural cross-reactivity. Am J Contact Derm 14: 179-187. [Crossref]

9. Bruton LL, Lazo JS, Parker KL (2006) Goodman \& Gilman'S the Pharmacological Basis of Therapeutics, $11^{\text {th }}$ edition.

10. Vind-Kezunovic D, Johansen JD, Carlsen BC (2011) Prevalence of and factors influencing sensitization to corticosteroids in a Danish patch test population. Contact Dermatitis 64: 325-329. [Crossref]

11. Baeck M, Marot L, Nicolas JF, Pilette C, Tennstedt D, et al. (2009) Allergic hypersensitivity to topical and systemic corticosteroids: a review. Allergy 64: 978-994. [Crossref]

12. Venturini M, Lobera T, del Pozo MD, Gonzalez I, Blasco A (2006) Immediate hypersensitivity to corticosteroids. J Investig Allergol Clin Immunol 16: 51-56. [Crossref]

13. Bennett ML, Fountain JM, McCarty MA, Sherertz EF (2001) Contact allergy to corticosteroids in patients using inhaled or intranasal corticosteroids for allergic rhinitis or asthma. Am J Contact Dermat 12: 193-196. [Crossref]

14. Mattioda G, Blanc A (2005) Glyoxal, Ullmann's Encyclopedia of Industrial Chemistry, Weinheim: Wiley-VCH.

15. Vatti RR, Ali F, Teuber S, Chang C, Gershwin ME (2013) Hypersensitivity Reactions to Corticosteroids. Clin Rev Allergy Immunol 47: 26-37. [Crossref]

16. Wilkinson SM, Jones MF (1996) Corticosteroid Usage and Binding to Arginine: Determinants of Corticosteroid Hypersensitivity. $\mathrm{Br} J$ Dermatol 135: 225-230. [Crossref]

17. Torres MJ, Canto G (2010) Hypersensitivity Reactions to Corticosteroids. Curr Opin Allergy Clin Immunol 10: 273-279. [Crossref]

18. Coopman S, Degreef, H, Dooms-Goossens A (1989) Identification of cross-reaction patterns in allergic contact dermatitis from topical corticosteroids. Br J Dermatol 121: 27-34. [Crossref]

19. Krasowski MD, Drees D, Morris CS, Maakestad J, Blau JL, et al. (2014) CrossReactivity of Steroid Hormone Immunoassays: Clinical Significance and TwoDimensional Molecular Similarity Prediction. BMC Clin Pathol 14: 33. [Crossref]

20. Goossens A, Matura M, Degreef H (2000) Reactions to corticosteroids: some new aspects regarding cross-sensitivity. Cutis 65: 43-45[Crossref]

21. Baker M, Empson R. The R, Fitzharris P (2015) Skin testing for immediate hypersensitivity to corticosteroids: a case series and literature review. Clin Exp Allergy 45: 669-676. [Crossref]

22. Cheam H, Butani L (2005) Immunoglobulin E mediated reactions to corticosteroids. Curr Allergy Asthma report 5: 22-27. 
23. Ventura MT, Calogiuri GF, Matino MG, Dagnello M, Buquicchio R, et al. (2003) Alternative Glucocorticoids for Use in Cases of Adverse Reaction to Systemic Glucocorticoids: a Study on 10 Patients. Br J Dermatol 148: 139-141. [Crossref]
24. De Sousa NG, Santa-Marta C, Morais Almeida M (2010) Systemic corticosteroid hypersensitivity in children. J Investig Allergol Clin Immunol 20: 529-532. [Crossref]

Copyright: $(02018$ Rodrigo CC. This is an open-access article distributed under the terms of the Creative Commons Attribution License, which permits unrestricted use, distribution, and reproduction in any medium, provided the original author and source are credited. 